\title{
Articular mobility in an African population
}

\author{
P. BEIGHTON,* L. SOLOMON, AND C. L. SOSKOLNE† \\ Department of Orthopaedic Surgery, University of the Witwatersrand, South Africa
}

There is considerable variation in the range of movements which are possible in the joints of normal individuals. In general, females are more mobile than males, while joint laxity decreases with age (Ellis and Bundick, 1956; Wynne-Davies, 1971).

Ethnic differences in joint mobility have also been described. For instance, Negroes and Indians have been shown to have a greater range of movements than Caucasians of the same age and sex (Harris and Joseph, 1949). Similarly, in an investigation in Cape Town, Indians were found to be more loose-jointed than indigenous Xhosa and Hlubi, who in turn had a greater degree of joint laxity than white South Africans (Schweitzer, 1970).

Articular mobility is a graded trait and at one end of the spectrum a considerable degree of joint laxity may occur in normal individuals (Wood, 1971). Apart from this form of hypermobility, joint laxity is also a component of a variety of genetically determined syndromes (McKusick, 1966; Beighton, 1970). It can also occur in the absence of other stigmata as a simple inherited entity (Sturkie, 1941; Carter and Sweetnam, 1958, 1960; Beighton and Horan, 1970).

It has been suggested that hypermobile individuals are prone to orthopaedic disorders, such as degenerative joint disease, dislocations, joint effusions, and muscular pains (Hass and Hass, 1958; Kirk, Ansell, and Bywaters, 1967; Grahame, 1971). Articular laxity has also been implicated as an important factor in the genesis of congenital dislocation of the hip (Wynne-Davies, 1970). For these reasons, hypermobility may well be of considerable clinical significance.

An epidemiological survey has recently been completed among the Tswana people of the Western Transvaal. The main aims of this investigation were the study of various bone and joint conditions, but the survey also provided an excellent opportunity for the measurement of the range of joint movements in a large number of individuals and for the assessment of the influence of age, sex, and somatotype on their articular mobility. The importance of joint laxity in the production of non-specific musculo-skeletal complaints was also evaluated.

The purpose of this paper is to present the results of this investigation and to discuss the clinical signifcance of the observations which were made.

\section{Methods}

(a) Outline of survey

The project was carried out in the Tswana village of Phokeng, which is situated at the foot of the Magaliesburg Hills, about 60 miles to the north-west of Johannesburg. The population, although living in a rural environment, were relatively sophisticated and readily co-operated in the investigation.

The survey had been preceded by a census, and by this means an epidemiologically valid section of the population was chosen for the study. Within this group, measurements of joint mobility were made on 1,081 individuals of all ages. Details of the demography and investigation techniques will be published elsewhere.

(b) Assessment of joint mobility

Joint laxity was measured during the clinical examination by means of a series of simple tests which have been used to assess the range of articular movements in a variety of hypermobility syndromes (Beighton and Horan, 1969). The method was a modification of a technique which was initially developed by Carter and Wilkinson (1964).

Patients were given a numerical score of 0 to 9 , one point being allocated for the ability to perform each of the following tests, as depicted in Figs 1 to 5:

(1) Passive dorsiflexion of the little fingers beyond $90^{\circ}$.

(2) Passive apposition of the thumbs to the flexor aspects of the forearms.

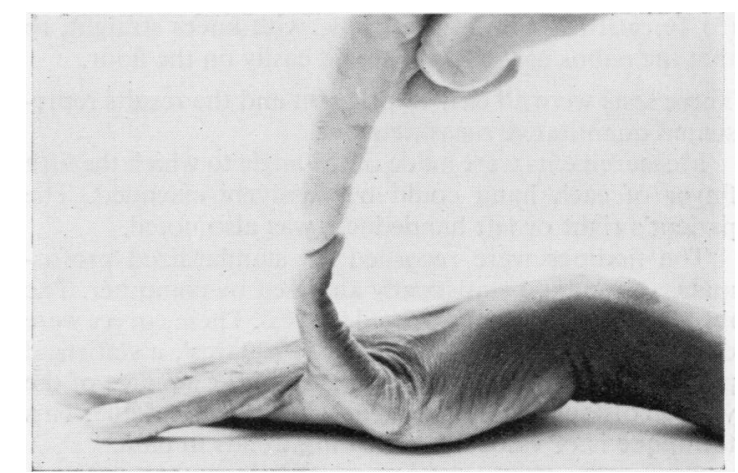

FIG. 1 Hyperextension of the fifth finger. In this particular illustration, the extension angle does not reach the required $90^{\circ}$ 


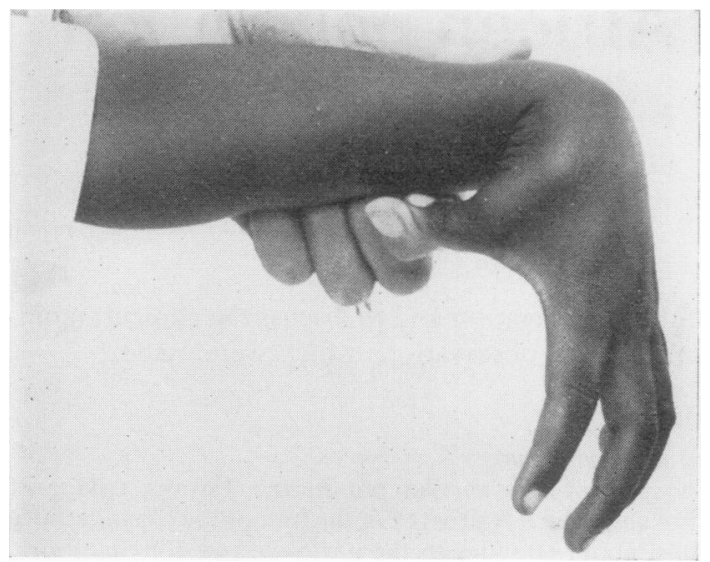

FIG. 2 Apposition of the thumb to the ventral aspect of the forearm

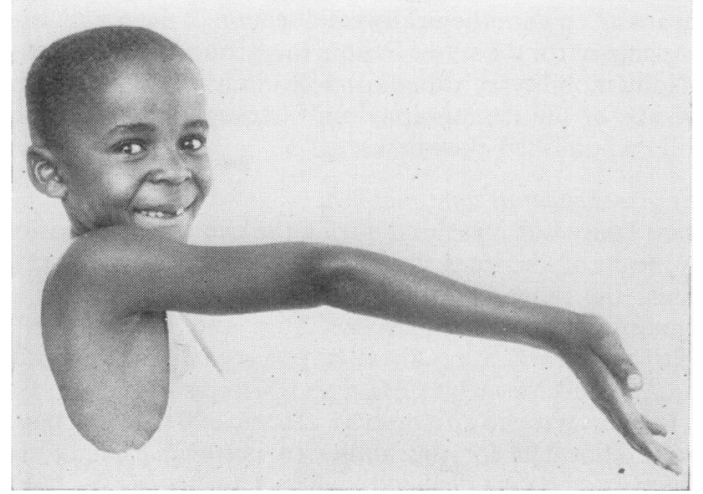

FIG. 3 Hyperextension of the elbow joint beyond $10^{\circ}$

(3) Hyperextension of the elbows beyond $10^{\circ}$.

(4) Hyperextension of the knees beyond $10^{\circ}$.

(5) Forward flexion of the trunk, with knees straight, so that the palms of the hands rested easily on the floor.

These tests were all easy to perform and the results represented quantitative measurements.

Measurements were made of the angle to which the fifth finger of each hand could be passively extended. The patient's right or left handedness was also noted.

The findings were recorded on standardized proformata, coded, and statistically analysed by computer. The results were expressed as 'fitted curves'. These curves were determined by the method of 'least squares', a statistical procedure which minimizes the sum of the squares of the vertical distances of the plotted points to a trend line. This technique is of value for indicating trends in data.

(c) Assessment of arthralgic symptoms

To facilitate the evaluation of their relationship with joint mobility, musculoskeletal symptoms were graded 0 to 4 . One point was scored for an affirmative answer to any of the following questions:

(i) Any pains in the hands or feet?

(ii) Any other joint pains?

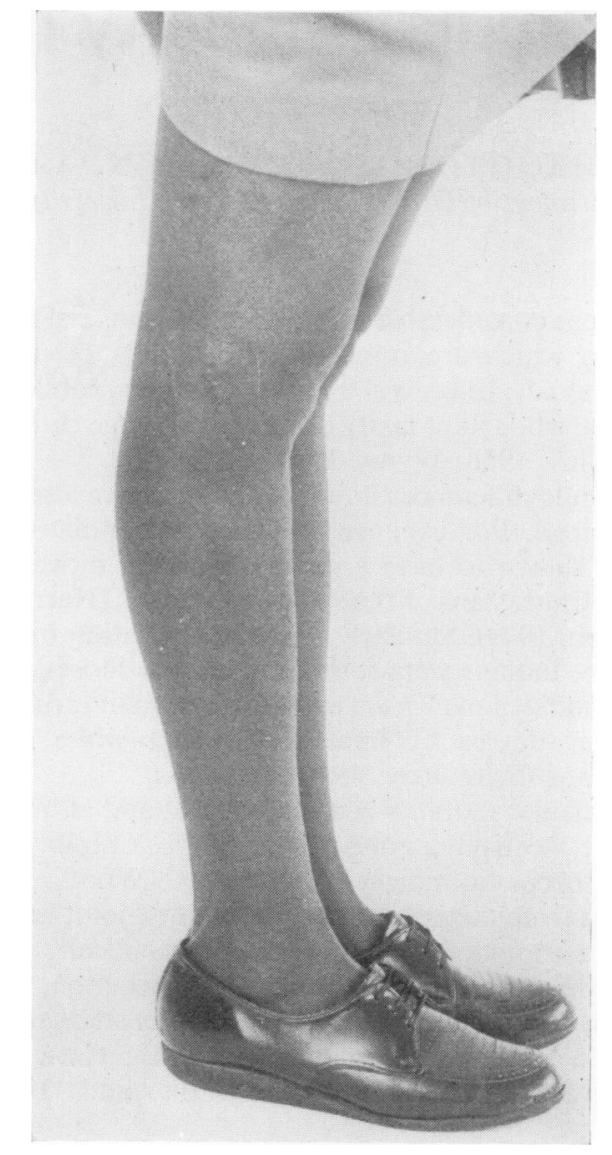

FIG. 4 Hyperextension of the knee joint beyond $10^{\circ}$

(iii) Any backache?

(iv) Any other pains in the limbs?

This method of assessment of arthralgic symptoms was relatively crude, but in view of the language barrier and the circumstances of the survey, it was the best that could be achieved. However, as all the individuals who were examined were graded in the same way, it is reasonable to assume that they could be compared on the basis of these observations.

(d) Assessment of somatotype

The relationship between joint laxity and body build was examined by correlating the mobility score with the ponderal index (PI) and metacarpal length.

The PI is an expression of somatotype which is derived $O$ by dividing the height in inches by the cube root of the weight in pounds (Acheson and Chan, 1969). This index was calculated for 101 patients in the survey in the 20 to 28-year age group, in whom mobility scores on the 0 to 9 scale were also available.

Skeletal configuration can be expressed in terms of the length of the 2 nd metacarpal. The distance between the proximal and distal articular surfaces of the left 2 nd metacarpal were measured for 94 individuals in the 20 to 28- 0 year age group, using antero-posterior radiographs of the 


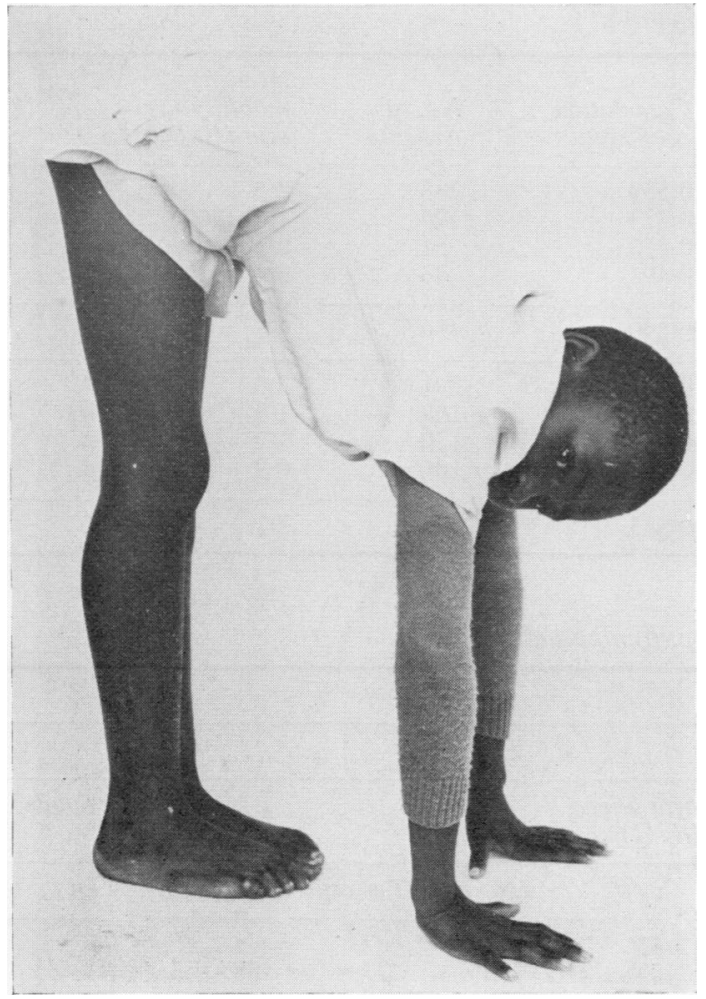

FIG. 5 Placing the palms of the hands flat on the floor while maintaining the knees in full extension

hands which had been taken at standard distances. The values obtained were then correlated with the mobility scores, for each of these investigation subjects.

\section{Results}

(a) Mobility score

A mobility score on the 0 to 9 scale was obtained in 1,081 individuals, of whom 168 males and 334 females

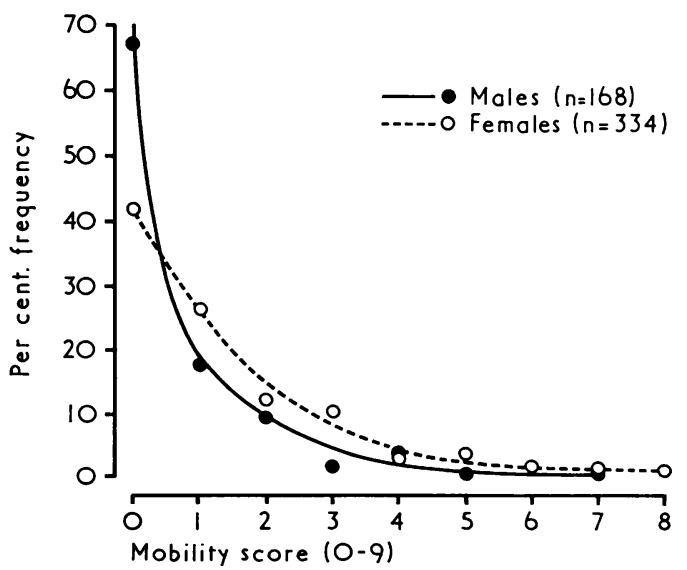

FIG. 6 Percentage frequency distribution of mobility score in adults were aged 20 or over. The percentage frequency distributions of the mobility scores in these groups are shown in Fig. 6. It is apparent from the fitted curves and the actual data that 94 per cent. of the males and 80 per cent. of the females achieved scores of 0,1 , or 2 . This range of movement can therefore be regarded as normal for adult Tswana.

The relationship between the mobility score, as an expression of joint laxity and age, is shown in Fig. 7. The curve indicates that at any age, females are more mobile than males. However, in both sexes, the degree of joint laxity diminishes rapidly throughout childhood, continuing to fall at a slower rate in adult life.

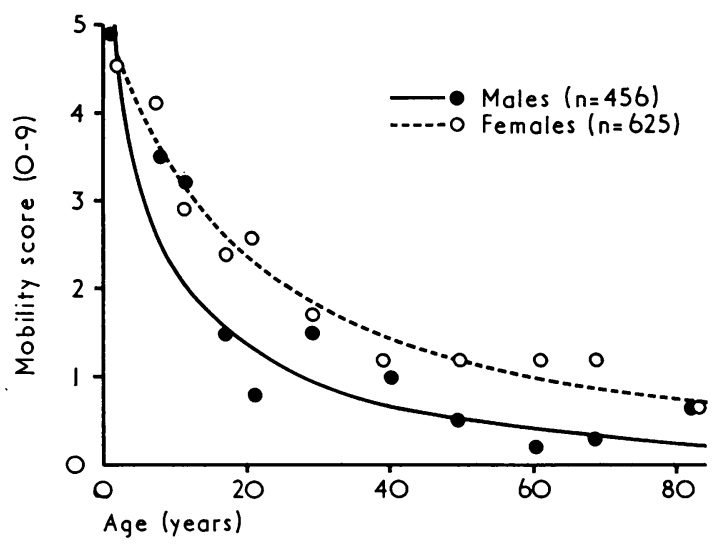

FIG. 7 Relationship between mobility score (0 to 9) and age, for males and females

\section{(b) Fifth finger extensibility}

The angle to which the fifth finger could be extended was recorded in 398 males and 537 females. The averages of these measurements were then compared with average mobility scores for males and females in four age cohorts (Table I, overleaf). The correlation coefficients within these cohorts varied between 0.373 and 0.559 .

When the extensibility angles and mobility scores were averaged for the total patients of each sex, correlation coefficients of 0.599 and 0.533 were obtained for males and females respectively.

(c) Joint laxity and handedness

The relationship between handedness and joint movements, as expressed by fifth finger extensibility, is shown in Table II (overleaf). These results, derived from 299 males and 361 females, are tabulated separately for each sex, in age cohorts. The extensibility value is less on the dominant side for each sex in almost every age group.

The occurrence of left-handedness in approximately 5 per cent. of males and 3 per cent. of females is in accordance with established norms for handedness in other populations. 
Table I Fifth finger extensibility and mobility score, by age and sex

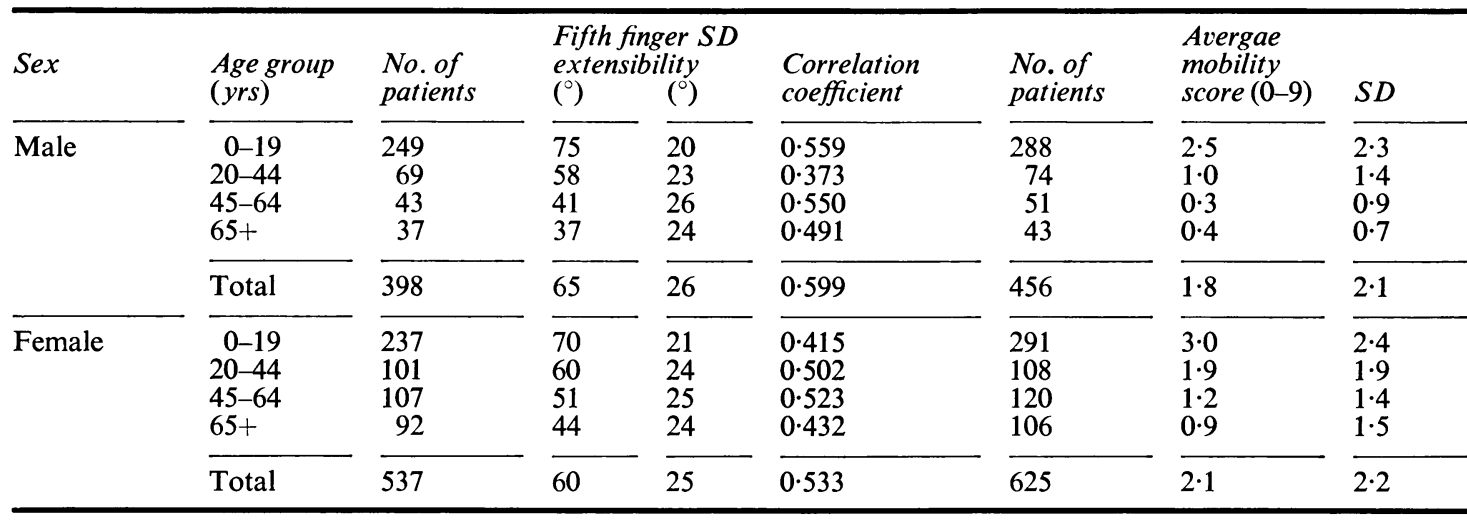

Table II Handedness and average fifth finger extensibility, by age and sex

\begin{tabular}{|c|c|c|c|c|c|c|c|c|c|}
\hline \multirow{4}{*}{ Sex } & \multirow{4}{*}{$\begin{array}{l}\text { Age group } \\
(y r s)\end{array}$} & \multicolumn{8}{|c|}{ Handedness } \\
\hline & & \multicolumn{4}{|c|}{ Right } & \multicolumn{4}{|l|}{ Left } \\
\hline & & \multicolumn{2}{|c|}{ Patients } & \multicolumn{2}{|c|}{$\begin{array}{l}\text { Average fifth finger } \\
\text { extensibility }\left({ }^{\circ}\right)\end{array}$} & \multicolumn{2}{|c|}{ Patients } & \multicolumn{2}{|c|}{$\begin{array}{l}\text { Average fifth fing } \\
\text { extensibility }\left({ }^{\circ}\right)\end{array}$} \\
\hline & & No. & Per cent. & Right & Left & No. & Per cent. & Right & Left \\
\hline \multirow[t]{2}{*}{$\begin{array}{l}\text { Male } \\
\text { (299) }\end{array}$} & $\begin{array}{l}0-19 \\
20-44 \\
45-64 \\
65+\end{array}$ & $\begin{array}{r}167 \\
55 \\
33 \\
29\end{array}$ & $\begin{array}{l}59 \\
19 \\
12 \\
10\end{array}$ & $\begin{array}{l}75 \\
54 \\
41 \\
35\end{array}$ & $\begin{array}{l}81 \\
63 \\
47 \\
46\end{array}$ & $\begin{array}{r}10 \\
4 \\
0 \\
1\end{array}$ & $\begin{array}{r}67 \\
27 \\
0 \\
6\end{array}$ & $\begin{array}{l}78 \\
88 \\
20\end{array}$ & $\begin{array}{l}75 \\
60 \\
20\end{array}$ \\
\hline & Total & $284^{*}$ & 100 & & & $15 \dagger$ & 100 & & \\
\hline \multirow[t]{2}{*}{$\begin{array}{l}\text { Female } \\
(361)\end{array}$} & $\begin{array}{l}0-19 \\
20-44 \\
45-64 \\
65+\end{array}$ & $\begin{array}{r}154 \\
72 \\
72 \\
51\end{array}$ & $\begin{array}{l}44 \\
21 \\
21 \\
14\end{array}$ & $\begin{array}{l}72 \\
58 \\
48 \\
45\end{array}$ & $\begin{array}{l}82 \\
69 \\
64 \\
55\end{array}$ & $\begin{array}{r}11 \\
0 \\
0 \\
1\end{array}$ & $\begin{array}{r}92 \\
0 \\
0 \\
8\end{array}$ & $\begin{array}{r}71 \\
0 \\
0 \\
10\end{array}$ & $\begin{array}{r}71 \\
0 \\
0 \\
10\end{array}$ \\
\hline & Total & $349 \pm$ & 100 & & & $12 \S$ & 100 & & \\
\hline
\end{tabular}

(d) Joint laxity and musculo-skeletal symptoms

The relationships between joint mobility on the 0 to 9 scale and musculo-skeletal symptoms are shown in Table III. In any age cohort, the score for musculoskeletal symptoms is always positively related to the mobility score. This relationship is most evident in females, the overall correlation coefficients being of the order of 0.797 for males and 0.957 for females.

\section{(e) Joint laxity and somatotype}

The correlation coefficients between the PI and the mobility score were -0.082 for the 47 males and +0.097 for the 54 females in whom this relationship had been investigated. Similarly, correlation coefficients between metacarpal length and mobility scores were -0.185 for the 46 males and +0.008 for the 48 females.

\section{Discussion}

The method of assessing joint mobility by means of a score based upon the range of movements of certain joints has proved its value in previous investigations. Although the great majority of normal adults score values of 0,1 , or 2 on the mobility scale, individuals with inherited hypermobility syndromes achieve scores at the top end of the scale (Beighton and Horan, 1969). It is therefore reasonable to conclude that the scale is valid for the measurement of joint mobility.

The results which were obtained demonstrate that the range of movements decreases with age, falling rapidly during childhood, and more slowly throughout adult life. However, at any age, females are consistently more hypermobile than males. These findings are in accordance with the observations which Ellis 
Table III Joint mobility (0 to 9) and musculo-skeletal symptoms, by age and sex

\begin{tabular}{|c|c|c|c|c|c|}
\hline \multirow{2}{*}{$\operatorname{Sex}$} & \multirow{2}{*}{$\begin{array}{l}\text { Age group } \\
\text { (yrs) }\end{array}$} & \multirow[b]{2}{*}{ Mobility score } & \multicolumn{2}{|c|}{ Patients } & \multirow{2}{*}{$\begin{array}{l}\text { Musculo-skeletal } \\
\text { symptoms }\end{array}$} \\
\hline & & & No. & Per cent. & \\
\hline \multirow[t]{6}{*}{ Male (168) } & $20-44$ & $\begin{array}{l}0-2 \\
3-5 \\
6-9\end{array}$ & $\begin{array}{r}65 \\
8 \\
1\end{array}$ & $\begin{array}{r}88 \\
11 \\
1\end{array}$ & $\begin{array}{l}0.123 \\
0.5 \\
0.0\end{array}$ \\
\hline & & Total & $74^{*}$ & 100 & - \\
\hline & $45-64$ & $\begin{array}{l}0-2 \\
3-5 \\
6-9\end{array}$ & $\begin{array}{r}49 \\
2 \\
0\end{array}$ & $\begin{array}{r}96 \\
4 \\
0\end{array}$ & $\begin{array}{l}0.959 \\
1.000 \\
0.0\end{array}$ \\
\hline & & Total & $51 \dagger$ & 100 & - \\
\hline & $65+$ & $\begin{array}{l}0-2 \\
3-5 \\
6-9\end{array}$ & $\begin{array}{r}43 \\
0 \\
0\end{array}$ & $\begin{array}{r}100 \\
0 \\
0\end{array}$ & $\begin{array}{l}1.512 \\
0.0 \\
0.0\end{array}$ \\
\hline & & Total & $43 \ddagger$ & 100 & - \\
\hline \multirow[t]{6}{*}{ Female (334) } & $20-44$ & $\begin{array}{l}0-2 \\
3-5 \\
6-9\end{array}$ & $\begin{array}{r}74 \\
27 \\
7\end{array}$ & $\begin{array}{r}68 \\
25 \\
7\end{array}$ & $\begin{array}{l}0.649 \\
0.704 \\
1.000\end{array}$ \\
\hline & & Total & $108 \S$ & 100 & - \\
\hline & $45-64$ & $\begin{array}{l}0-2 \\
3-5 \\
6-9\end{array}$ & $\begin{array}{r}100 \\
19 \\
1\end{array}$ & $\begin{array}{r}83 \\
16 \\
1\end{array}$ & $\begin{array}{l}1 \cdot 200 \\
1.579 \\
2.000\end{array}$ \\
\hline & & Total & $120 \|$ & 100 & - \\
\hline & $65+$ & $\begin{array}{l}0-2 \\
3-5 \\
6-9\end{array}$ & $\begin{array}{r}92 \\
11 \\
3\end{array}$ & $\begin{array}{r}87 \\
10 \\
3\end{array}$ & $\begin{array}{l}1 \cdot 402 \\
1.909 \\
2 \cdot 333\end{array}$ \\
\hline & & Total & $106 \pi$ & 100 & - \\
\hline
\end{tabular}

and Bundick (1956) made during their investigations on American Negroes.

On a basis of anatomical and radiological studies of finger joints, Schweitzer (1970) postulated that the factor which limited articular movements was tension in the volar plate and flexor tendons. These structures are largely composed of collagen which, in the skin at least, becomes stiffer in the elderly (Ridge and Wright, 1966). In addition, the intrafibrillar cross-links in the collagen are increased with advancing age (Verzar, 1957). The reduction in joint mobility with ageing is readily explicable on the basis of these changes.

A positive relationship exists between the mobility score and the angle to which the fifth finger can be passively extended. This relationship is independent of age and sex, and measurements of this angle may therefore be used in the assessment of overall joint mobility. However, it is not always an easy matter to make accurate measurements of the fifth finger extensibility angle. In view of the simplicity of the 0 to 9 scale and of the fact that it takes movements of a wide range of joints into consideration, this method is to be preferred for the assessment of generalized articular mobility.

The fifth finger hyperextensibility measurements show mobility in this pair of joints to be inversely related to left and right handedness. In other words, the range of movements is almost invariably diminished on the dominant side. Although exact measurements were not made, a strong clinical impression has been gained that all the other paired joints conform to this pattern.

The findings indicate that a significantly positive relationship exists between joint laxity and arthralgic complaints in individuals of any age and sex. This observation supports the hypothesis of Kirk and others (1967) who postulated that hypermobile individuals may be predisposed to musculo-skeletal problems.

It is generally assumed that tall, thin individuals tend to be more loose jointed than those with a short stocky physique. For this reason, correlations were sought between joint mobility and body build, as expressed by PI and second metacarpal length. In 
neither case did any significant correlation exist and it is therefore unlikely that there is any association between joint mobility and these facets of somatotype.

The methodology of this survey was straightforward, and the mobility measurements were easy to carry out. It is our intention to apply these techniques to other population groups, in order to assess ethnic variations in articular laxity, to confirm the observed relationships between joint mobility, age, and sex, and to substantiate the association between joint laxity and musculo-skeletal problems.

\section{Summary}

Joint mobility was measured in 1,081 members of a Tswana community in the Western Transvaal, as part of an epidemiological survey of bone and joint conditions. The method, using an assessment of the range of movements of a predetermined set of joints, was easy to carry out and gave reproducible results.

Joint mobility diminished with ageing, falling rapidly as childhood progressed, and more slowly throughout adult life. Marked differences were present between the sexes, females having a greater degree of joint laxity than males of the same age.

A positive correlation existed between the mobility score and the degree of passive hyperextension which could be achieved by the fifth finger. The range of movements of the fifth finger was greater on the nondominant side in both left and right handed individuals.

Arthralgic complaints were positively related to joint laxity in both sexes. Physique, as expressed by ponderal index and metacarpal length, was not found to bear any relation to joint mobility.
This research was supported jointly by the Orthopaedic Chair Trust Fund and The Carl and Emily Fuchs Foundation.

We are indebted to the President of the Human Sciences Research Council, Pretoria, for his kind provision of computer facilities, and to the secretarial and photographic staff of the Orthopaedic Department, for their assistance in the preparation of this article. We are especially grateful to the Tswana of Phokeng for their good-natured participation in the survey, and to Chief Mokgatle and the Department of Bantu Administration for permission to undertake this investigation. Mrs. Fifi Sparrow and Miss Liz Paget typed the manuscript with enthusiasm and efficiency. P.B. was in receipt of a Geigy Fellowship awarded by the Arthritis and Rheumatism Council of Great Britain

\section{Discussion}

DR. R. GR AH AME (London) We have recently surveyed the joint mobility of 300 London schoolchildren and have also found a very rapid fall-off of joint mobility between the ages of 5 and 11 years. We found no significant sex difference and there was no difference between the dominant and the non-dominant sides. The extensibility of the fifth metacarpophalangeal joint was the most valuable and sensitive technique. The other methods recommended by Carter and Wilkinson (1964) were not sensitiv8 enough to differentiate between the age groups that examined.

PROF. BEIGHTON Dr. Grahame is to be congratulated on his studies. I think that our respective results are not incompatible as we were looking at different things from a different view point. Dr. Grahame was focusing on a specific joint and examining it in a scientific and sophisticated way. We were conducting a wider investigation of a diffuse situation.

\section{References}

Acheson, R. M., AND Yick-Kwong Chan (1969) J. chron. Dis., 21, 543 (New Haven Survey of Joint Diseases: Prediction of serum uric acid in a general population)

Beighton, P. (1970) 'The Ehlers-Danlos Syndrome'. Heinemann, London

- AND Horan, F. (1969) J. Bone Jt Surg., 51B, 444 (Orthopaedic aspects of the Ehlers-Danlos syndrome)

, (1970) Ibid., 52B, 145 (Dominant inheritance in familial generalised articular hypermobility)

CARTer, C. O., AND SweETMAN, R. (1968) Ibid., 40B, 664 (Familial joint laxity and recurrent dislocation of the patella)

- (1960) Ibid., 42B, 721 (Recurrent dislocation of the patella and of the shoulder)

Ellis, F. E., AND BUNDICK, W. R. (1956) Arch. Derm., 74, 22 (Cutaneous elasticity and hyperelasticity)

Grahame, R. (1971) Proc. roy. Soc. Med., 84, 692 (Joint hypermobility-clinical aspects)

Harris, H., and Joseph, J. (1949) J. Bone Jt Surg., 31B, 547 (Variation in extension of the metacarpophalangeal and interphalangeal joints of the thumb)

HaSs, J., AND HASs, R. (1958) Ibid., 40A, 663 (Arthrochalasis multiplex congenita)

Kirk, J. A., Ansell, B. M., and Bywaters, E. G. L. (1967) Ann. rheum. Dis., 26, 419 (The hypermobility syndrome. Musculoskeletal complaints associated with generalized joint hypermobility)

McKusick, V. A. (1966) 'Heritable Disorders of Connective Tissue', 3rd ed. Mosby, Saint Louis

RIDGE, M. D., AND WRIGHT, V. (1966) Gerontologia (Basel), 12, 174 (The ageing of skin: a bio-engineering approach) SCHweitzer, G. (1970) S. Afr. med. J., 44, 246 (Laxity of metacarpophalangeal joints of finger and interphalangeal joint of the thumb: A comparative interracial study)

Sturkie, P. D. (1941) J. Hered., 32, 232 (Hypermobile joints in all descendants for two generations)

VerZAR, F. (1957) In 'Connective Tissue', a Symposium organized by the C.I.O.M.S., Blackwell, Oxford, ed. R. E. Tunbridge, p. 208.

Wood, P. H. N. (1971) Proc. roy. Soc. Med., 64, 690 (Is hypermobility a discrete entity?)

WynNe-DAvies, R. (1970) J. Bone Jt Surg., 52B, 704 (Acetabular dysplasia and familial joint laxity: two etiological factors in congenital dislocation of the hip)

— (1971) Proc. roy. Soc. Med., 64, 689 (Familial joint laxity) 